\title{
Prevalence of asymptomatic myocardial ischaemia in diabetic subjects
}

\author{
M J Koistinen
}

\begin{abstract}
Objective-To compare the prevalence of silent myocardial ischaemia associated with coronary artery disease in diabetic subjects with that in controls of similar age and sex.

Design-A controlled study in which subjects with positive findings on exercise electrocardiography, 24 hour electrocardiographic recording, or dynamic thallium scintigraphy (diabetics only) underwent coronary angiography.
\end{abstract}

Setting-Academic medical centre; referral based cardiology clinic.

Subjects-136 Diabetic subjects, of whom 72 ( 33 women, 39 men (mean age 46.0)) were insulin dependent and 64 (19 women, 45 men (mean age 49.3)) non-insulin dependent. 80 Controls matched for age and sex; all were clients of the Occupational Health Service of Oulu University Central Hospital or the State Occupational Health Service Station in Oulu in whom diabetes had been excluded by a glucose tolerance test.

Interventions-Any subject showing signs of myocardial ischaemia was referred for cardiac catheterisation.

Main outcome measures-Exercise electrocardiography and 24 hour electrocardiographic recording were regarded as positive if there were ST depressions of $\geqslant 1 \mathrm{~mm}$ that were planar or downsloping and persisted for $\mathbf{0 . 0 8}$ seconds after the J point. Thallium tomographic imaging. With cardiac catheterisation, coronary artery lesions were classified as significant if half or more of the vessel lumen was narrowed, or insignificant if such narrowing was less than half.

Results-40 (29\%) Diabetics and four (5\%) controls had positive results in one or more of the non-invasive tests. Coronary angiography was performed on 34 of the diabetics (six refused); 12 had significant coronary artery narrowing; seven had unimportant atherosclerosis; 15 had patent coronary arteries. Among the controls only one had unimportant atherosclerosis; the other three had patent arteries.

Conclusions-These results confirm the high prevalence of asymptomatic myocardial ischaemia in diabetics. Non-invasive screening of diabetic subjects, however, does not seem justified because of the low preset probability of the presence of the disease and the inaccuracy of the available test methods.

Cardiovascular Division, Department of Medicine Oulu University, SF-90220 Oulu, Finland $M$ J Koistinen, MD, cardiologist

Correspondence to: Dr Koistinen.

\section{Introduction}

Coronary artery disease is an important complication of diabetes mellitus, representing the ultimate cause of death in more than half of all patients with this disease. The concept of silent myocardial ischaemia that has emerged in recent years has been divided into three groups: totally silent ischaemia (type I); silent ischaemia after infarction (type II); and mixed silent ischaemia (type III), in which patients have both painless and symptomatic periods of myocardial ischaemia. ${ }^{2}$ It has been reported that ischaemia with symptoms might be equally important as that without.

Data from the Framingham study showed that $12 \%$ of infarctions were totally silent. ${ }^{+}$Patients with diabetes have an increased risk of developing such silent infarctions. ${ }^{5}$ There are several reports showing an excess mortality from coronary heart disease in diabetic populations, ${ }^{6-8}$ but only a few surveys have been aimed at assessing the prevalence of asymptomatic coronary artery disease with silent myocardial ischaemia (type I) in diabetic populations. This study was designed to estimate the prevalence of angiographically confirmed silent coronary artery disease with active myocardial ischaemia in a diabetic population compared with that of a non-diabetic control group comprised of patients of similar age and sex.

\section{Subjects and methods}

An invitation to enter the study was posted to all diabetic members of the local diabetic association. Out of 338 patients contacted, 170 were not willing to participate and 32 did not fulfil the inclusion criteria. This left 136 diabetic subjects who could be studied, of whom 72 (33 women; 39 men (mean age 46)) were insulin dependent diabetics who had had ketosis prone diabetes from a young age. The other 64 (19 women; 45 men (mean age 49.3)) were non-insulin dependent diabetics who were being treated with diet alone or with diet combined with oral hypoglycaemic drugs, were not ketosis prone, and showed pronounced $\mathrm{C}$ peptide activity after glucagon stimulation (mean increase in $\mathrm{C}$ peptide activity after stimulation being 1.5). All the diabetic subjects fulfilled the World Health Organisation criteria for idiopathic diabetes mellitus.

The exclusion criteria were: $(a)$ age $<35$ or $>60$; (b) duration of insulin dependent diabetes less than five years; (c) symptoms or clinical evidence of ischaemic heart disease (using the Rose questionnaire); $(d)$ the taking of drugs to lower plasma lipid concentrations; (e) the presence of severe renal disease (serum creatinine concentration over $200 \mathrm{mmol} / \mathrm{l}) ;(f)$ the presence of proliferative retinopathy; $(g)$ the presence of thyroid disease, overt malignant tumours, or alcoholism; $(h)$ the presence of any severe disease that would contraindicate performing the maximal exercise test.

The control group comprised clients of the Occupational Health Service of Oulu University Central Hospital and the State Occupational Health Service Station in Oulu. An invitation was posted to 145 subjects who were of similar age and sex to the diabetic population. Of these, 60 refused to participate, five did not fulfil the inclusion criteria, and 80 were willing to be studied. Nurses, assistant nurses, and doctors were excluded from the control group. The general exclusion criteria for the control subjects were the same as for the diabetic patients. An oral $75 \mathrm{~g}$ glucose tolerance test was performed on all control subjects and those without normal results were excluded.

Fifteen diabetics and five controls were taking 
$\beta$ blocking agents for hypertension; none was receiving calcium antagonists or digitalis treatment. The $\beta$ blocking treatment was stopped two days before the examination.

All the subjects gave their informed consent for the examination, which was approved by the ethical committee of the medical faculty of the University of Oulu.

Maximal exercise electrocardiography, exercise thallium tomographic imaging, and a 24 hour electrocardiographic recording were performed on the diabetic subjects who were eligible for the study. Any patient who showed signs of myocardial ischaemia was referred for cardiac catheterisation. The control subjects underwent exercise electrocardiography and a 24 hour electrocardiographic recording, after which dynamic thallium scintigraphy and cardiac catheterisation were performed if there were any ischaemic findings. The ethical committee objected to the performing of thallium scintigraphy on control subjects who had no evidence of myocardial ischaemia because of the possible radiation hazard.

Exercise electrocardiography-A maximal exercise test was performed on an electrically braked bicycle ergometer starting at $30 \mathrm{~W}$ and increasing the workload each minute by $15 \mathrm{~W}$ for men and $10 \mathrm{~W}$ for women. The final workload was the maximum achieved by the individual and was determined by age or fatigue. The maximal heart rate was calculated on the basis of the following equation: $205-1 / 2$ (age), ${ }^{9}$ and the target was to achieve at least $85 \%$ of this maximal heart rate. Twelve lead electrocardiograms were recorded before the test, at the end of every second minute during it, and up to five minutes afterwards. Recordings were made more often if the patient developed changes in the electrocardiogram, abnormal blood pressure reactions, or symptoms. The result was considered positive if there were ST depressions of $\geqslant 1$ $\mathrm{mm}$ that were planar or downsloping and persisted for 0.08 seconds after the $\mathrm{J}$ point.

Thallium-201 scintigraphy-Thallium scintigraphy was performed using the same protocol as for the exercise electrocardiography. Thallium-201 $(3 \mathrm{mCi}$ (110 MBq)) was injected 30 to 60 seconds before completion of the ergometric exercise and thallium tomographic imaging was performed. ${ }^{10}$

TABLE I-Clinical characteristics of diabetic and control subjects

\begin{tabular}{|c|c|c|c|}
\hline Characteristic & $\begin{array}{c}\text { Insulin dependent } \\
\text { diabetics } \\
(\mathbf{n}=72)\end{array}$ & $\begin{array}{c}\text { Non-insulin dependent } \\
\text { diabetics } \\
(n=64)\end{array}$ & $\begin{array}{l}\text { Controls } \\
(\mathrm{n}=80)\end{array}$ \\
\hline Mean (SD) age (years) & $46 \cdot 1(7 \cdot 3)$ & $49 \cdot 3(6 \cdot 8)$ & $46 \cdot 3(7 \cdot 4)$ \\
\hline Sex ratio $(\mathrm{f}: \mathrm{m})$ & $33: 39$ & $19: 45$ & $31: 49$ \\
\hline \\
\hline Mean (SD) & $13 \cdot 5(7 \cdot 8)$ & $9 \cdot 6(6 \cdot 0)$ & \\
\hline Range & $5-36$ & $1-36$ & \\
\hline \multicolumn{4}{|l|}{ Treatment of diabetes $(\mathrm{No}(\%))$ : } \\
\hline Insulin & $71(99)$ & $15(23)$ & \\
\hline Insulin and tablets & l(1) & $1(2)$ & \\
\hline Tablets & 0 & $24(38)$ & \\
\hline Diet only & 0 & $24(38)$ & \\
\hline Glycated haemoglobin (\%(SD)) & $11 \cdot 4(2 \cdot 3)$ & $11 \cdot 0(2 \cdot 7)$ & \\
\hline Blood glucose concentration $(\mathrm{SD})(\mathrm{mmol} / \mathrm{l})$ & $11.0(3.7)$ & $10 \cdot 7(3.9)$ & \\
\hline Cholesterol concentration $(\mathrm{SD})(\mathrm{mmol} / \mathrm{l})$ & $5 \cdot 8(1 \cdot 0)$ & $5 \cdot 9(1 \cdot 2)$ & $5 \cdot 8(1 \cdot 1)$ \\
\hline No $(\%)$ with hypertension & $10(14)$ & $22(34)$ & $7(9)$ \\
\hline No $(\%)$ of smokers & $19(26)$ & $7(11)$ & $23(29)$ \\
\hline No $(\%)$ with family history of diabetes & $26(36)$ & $32(50)$ & $41(51)$ \\
\hline
\end{tabular}

24 Hour electrocardiographic recording-A two channel recording was obtained using two pairs of bipolar electrodes applied precordially. In all patients one channel recorded lead V5 with the indifferent electrode over the manubrium and the exploring electrode in the precordial V5 position, while the other channel recorded inferior changes resembling aVF with the exploring electrode at the xiphisternum and the indifferent electrode at the left sternoclavicular joint. Monitor leads were attached to the electrodes (Red Dot, 3M) and secured with adhesive tapes. A 24 hour two channel recording was then obtained on magnetic tape using a frequency modulated recorder. The tapes were analysed at 60 times normal speed using a computerised analysing system (Pathfinder). All portions of the electrocardiographic recording suggestive of $\geqslant 1 \mathrm{~mm} \mathrm{ST}$ depression were printed out at a paper speed of $25 \mathrm{~mm} / \mathrm{s}$ and evaluated visually. A significant ST depression was defined as a planar or downsloping shift in the ST segment of $\geqslant 1 \mathrm{~mm}$ measured 0.08 seconds after the $\mathrm{J}$ point and persisting for at least 30 seconds. Position and hyperventilation tests were performed before the recording was made.

Cardiac catheterisation-All subjects who showed signs of myocardial ischaemia in the non-invasive tests were referred for cardiac catheterisation. Thirty four diabetics (six refused) and four controls underwent left sided cardiac catheterisation including selective coronary arteriography in caudal and cranial projections performed by the Judkins method. Biplanar left ventricular cineangiograms and left ventricular pressure recordings were performed. " Coronary artery lesions were classified as significant if half or more of the coronary artery lumen was narrowed or insignificant if such narrowing was less than half. The angiographic findings were interpreted by two experienced observers.

Statistical analysis-The Fisher's test of exact probability was used to evaluate differences in frequencies.

\section{Results}

The clinical characteristics of the diabetic and control subjects are shown in table I. There were no differences in the smoking habits, serum cholesterol concentrations, prevalence of hypertension, or family history of coronary artery disease between the diabetic population and the control group.

The non-invasive test results and the coronary angiography findings for the diabetic and control subjects are shown in the figure. The results were analysed for the insulin dependent diabetics aged more than 50 and for those aged less than 50 and similarly for the non-insulin dependent diabetics. These results are shown in table II. Evidence of myocardial ischaemia with one or more of the non-invasive tests was found in 40 of the diabetic patients. Both thallium scintigraphy and exercise electrocardiography were positive in 11 subjects, but nobody had positive results on all three non-invasive tests. No difference was found in the prevalence of test results showing ischaemia between diabetics older than $50(20 / 63(32 \%))$ and those

TABLE II - Relations of positive non-invasive test results and coronary angiography in insulin dependent and non-insulin dependent diabetics aged more than 50 and less than 50

\begin{tabular}{|c|c|c|c|c|c|c|c|c|c|c|c|c|}
\hline & \multicolumn{6}{|c|}{ Insulin dependent diabetics } & \multicolumn{6}{|c|}{ Non-insulin dependent diabetics } \\
\hline & \multicolumn{2}{|c|}{$>50$ years $(n=30)$} & \multicolumn{2}{|c|}{$<50$ years $(n=42)$} & \multicolumn{2}{|c|}{ Total $(n=72)$} & \multicolumn{2}{|c|}{$>50$ years $(n=33)$} & \multicolumn{2}{|c|}{$<50$ years $(\mathrm{n}=31)$} & \multicolumn{2}{|c|}{ Total $(n=64)$} \\
\hline & No & $\%(95 \% \mathrm{CI})$ & No & $\%(95 \% \mathrm{CI})$ & No & $\%(95 \% \mathrm{CI})$ & No & $\%(95 \% \mathrm{CI})$ & No & $\%(95 \% \mathrm{CI})$ & No & $\%(95 \% \mathrm{CI})$ \\
\hline $\begin{array}{l}\text { Positive non-invasive test result } \\
\text { Important coronary artery disease on }\end{array}$ & 8 & 27 (12 to 45$)$ & 9 & $21(10$ to 36$)$ & 17 & $24(14$ to 35$)$ & 12 & $36(20$ to 55$)$ & 11 & $35(19$ to 55$)$ & 23 & $36(24$ to 49$)$ \\
\hline angiography & 3 & 10 (2 to 26$)$ & 4 & 10 (3 to 23$)$ & 7 & $10(4$ to 19$)$ & 3 & $9(2$ to 24$)$ & 2 & $6(1$ to 21$)$ & 5 & 8 (3 to 18$)$ \\
\hline
\end{tabular}




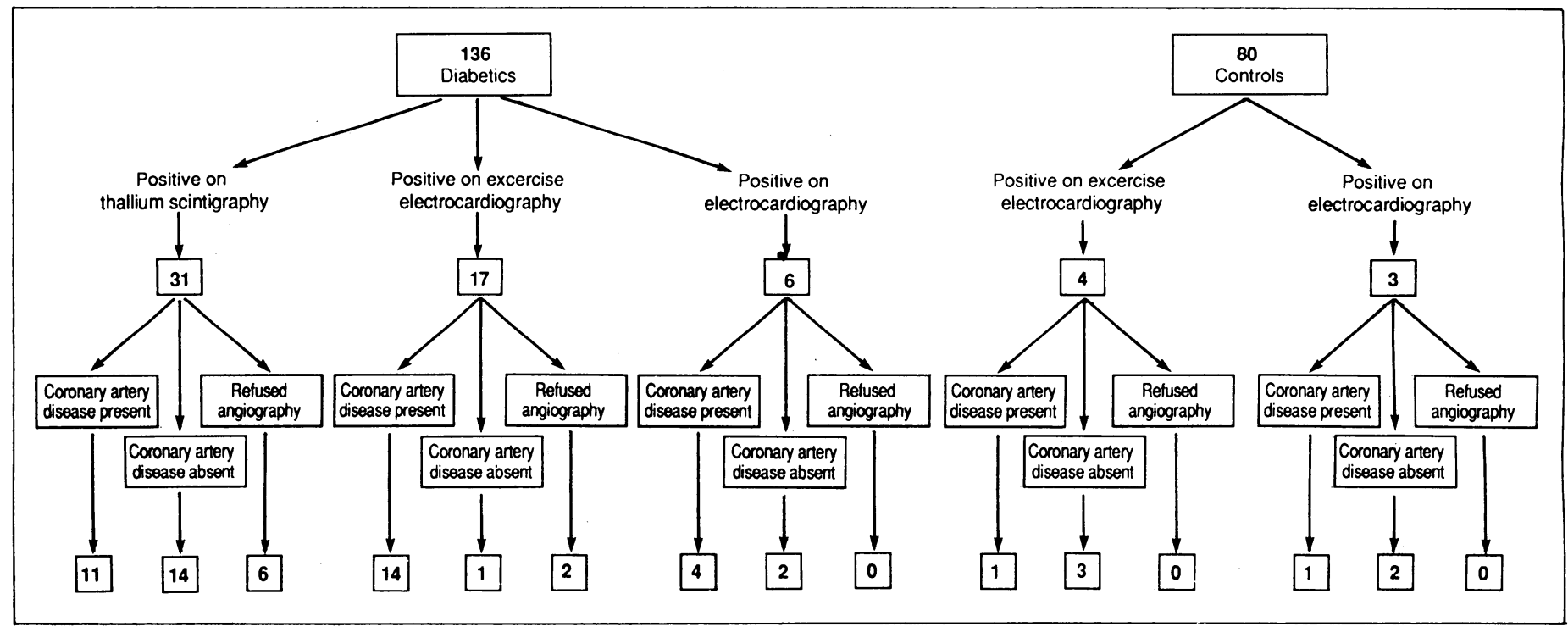

Non-invasive test results related to results of coronary angiography younger than $50(20 / 73 \quad(27 \%))$. Furthermore, no differences were found in any of the positive non-invasive test results between women (13/52 (25\%)) and men $(27 / 84(32 \%))$.

Coronary angiography showed significant coronary artery disease in 12 of the diabetic patients, of whom five exhibited one vessel disease, five two vessel disease, and two three vessel disease. In six of these patients the coronary artery narrowing was greater than $70 \%$ of the luminal diameter, and in the other six it was between 50 and $70 \%$. Unimportant coronary atherosclerosis was detected in seven of the diabetic patients and patent coronary arteries were found in 15 . Six of the diabetic patients who had positive findings in at least one of the non-invasive tests refused coronary angiography. There was no difference in the prevalence of angiographically proved coronary artery disease between the diabetics older than $50(6 / 63(10 \%))$ and those younger than $50(6 / 73(8 \%))$ or between women $(4 / 52(8 \%))$ and men $(8 / 84(10 \%))$. On retaking the history in the 12 diabetics with angiographically documented coronary artery disease none of them reported a history of either angina or exertional dyspnoea.

Non-invasive tests showed the presence of myocardial ischaemia in four of the control subjects. Of these, coronary angiography disclosed unimportant coronary artery atherosclerosis in one (a man) and patent coronary arteries in the other three.

In this study the incidence of asymptomatic coronary artery disease with active myocardial ischaemia in the diabetic population was $9 \%(12 / 136)$ ( $95 \%$ confidence interval 5 to $15 \%$ ), which was higher than that for the control group (1.3\% (0 to $7 \%)$; $\mathrm{p}<0.005)$. The prevalences of angiographically proved coronary artery disease in different subgroups are presented in table II.

\section{Discussion}

Numerous studies have suggested that silent myocardial ischaemia is more common in diabetic patients than in others, ${ }^{12-14}$ but most have included only patients with evidence or symptoms of heart disease. Abenavoli et al found a high prevalence of silent myocardial ischaemia in asymptomatic diabetic men documented by thallium scintigraphy and exercise electrocardiography, but the results were not related to findings at coronary angiography. ${ }^{15}$ The small number of studies that have assessed the occurrence of type I silent myocardial ischaemia in the general population have found its prevalence to be between $2 \%$ and $3 \%,{ }^{16} 17$ but none has related the positive non-invasive test findings to findings at coronary angiography in otherwise healthy diabetics. The incidence of at least $9 \%$ for the occurrence of asymptomatic coronary artery disease with active myocardial ischaemia found in this study concurs with the findings of others of an increased incidence of silent myocardial ischaemia in diabetic patients. My findings might have underestimated the true prevalence because six of the diabetic subjects with positive non-invasive test results refused coronary angiography. I also found no difference in the occurrence of asymptomatic coronary artery disease between men and women, and this finding is consistent with the assumption that diabetic women lose their protection against coronary artery disease. ${ }^{18}$ Furthermore, no differences were found in the prevalence of asymptomatic ischaemia between diabetics aged over 50 and those aged under 50 .

The results of this study also showed a remarkably low prevalence of asymptomatic coronary artery disease in otherwise healthy middle aged subjects without diabetes. Our control group might not have been fully representative of the general population because all were employed and all were recruited through the occupational health service. Thallium scintigraphy was not performed on the controls and therefore the results might have underestimated the true prevalence. Despite these limitations, these data strongly support the view that asymptomatic coronary artery disease is rare in healthy people without diabetes.

Because false negative non-invasive test results might have also influenced the prevalence figures, it was impossible to calculate absolute figures for asymptomatic coronary artery disease in these populations. This would have necessitated catheterisation of the whole series, including the controls, which was ethically unacceptable.

Coronary angiography showed that a comparatively high number of patients in this young diabetic population had asymptomatic coronary artery disease, the prevalence apparently being twice or three times that of the average for the general population. Even so, the occurrence of coronary artery disease in an otherwise healthy asymptomatic diabetic population is so small that according to Bayes's theorem the expected frequency of false positive test results in this kind of population would be fairly high. ${ }^{19}$ This was evident in this series because only 12 out of 34 diabetic patients with at least one positive non-invasive test result had angiographically important coronary artery disease on catheterisation. Non-invasive screening of this particular risk group does not therefore seem to be warranted. 
This study was supported by grants from the Finnish Foundation for Cardiovascular Research and the Ida Montin Foundation, Helsinki, Finland. CP, Bradley RF: Chrislieb aR, Soeldner JS, eds. Joslin's diabees Philadelphia: La and Febiger, 1985:553-82.

Cohn PF Silent myordialischemia: classification prevalence and prognosis. Am F. Med 1985;79: suppl 3A):2-6.

3 Asser ME. Prognosis in stable angina pectoris and silent mvocardial ischemia. A $m$ F Cardiol 1988;61:19F-21F

+ Margolis JR, Kannel WB, Feinleib M, Dawber TR, McNamara PM. Clinical features of unrecognized myocardial infarction: an update on the Framingham study. N Engl f. Med 1984;311:1144-7.

5 Bradley RF, Schonfeld A. Diminished pain in diabetic patients with acute myocardial infarction: Geriatrics 1962;17:322-6.

6 Pell S, D'Alonzo CA. Factors associated with long-term survival of diabetics. FA.MA 1970;214:1833-40.

Kannel WB, McGee DL. Diabetes and cardiovascular disease. The Framingham study. $f A M A$ 1979;241:2035-8

8 Herman JB, Medalie JH, Goldbourt U. Differences in cardiovascular morbidity and mortality between previously known and newly diagnosed adult diabetics. Diabetologia 1977;13:229-34.

9 Arstila M, Kallio V, Seppänen A. Clinical exercise testing. Standards for procedures and recommendations for the interpretation. Publications of the procedures and recommendations for the interp

10 Huikuri HV, Korhonen UR, Airaksinen KEJ, Ikäheimo MJ, Heikkilä J,
Takkunen JT. Comparison of dipyridamole-handgrip test and bicycle exercise for thallium tomographic imaging. Am 7 Cardiol 1988;61:264-8

11 Huikuri HV, Ikäheimo $M J$, Linnaluoto $M M K$, Takkunen JT. Left ventricula response to isometric exercise and its value in predicting the change in ventricular function after mitral valve replacement for mitral regurgitation. Am F Cardiol 1983;51:1110-5.

12 Chiariello $\mathrm{M}$, Indolfi $\mathrm{C}$, Cotecchia MR, Sifola C, Romano M, Condorelli $M$ Asymptomatic transient ST changes during ambulatory ECG monitoring in diabetic patients. Am Heart f 1985;110:529-34.

13 Nesto RW, Phillips RT, Kett KG, et al. Angina and exertional myocardia ischemia in diabetic and non-diabetic patients: assessment by exercise ischemia in diabetic and non-diabetic patients: assess

14 Bellet S, Roman L. The exercise test in diabetic patients as studied by radioelectrocardiography. Circulation 1967:36:245-54.

15 Abenavoli T, Rubler S, Fisher VJ, Axelrod HI, Zuckerman KP. Exercise testing with myocardial scintigraphy in asymptomatic diabetic males. Circulation 1981;63:54-6

16 Erikssen J, Thaulow E. Follow up of patients with asymptomatic myocardial ischemia. In: Rutishauser W, Roskamm H, eds. Silent myocardial ischemia. Berlin: Springer Verlag, 1984:156-64.

17 Froelicher VF, Thompson AJ, Longo MR Jr, Triebwasser JH, Lancaster MC Value of exercise testing for screening asymptomatic men for latent coronary artery disease. Prog Cardiovasc Dis 1976;18:265-76.

18 Kereiakes DJ, Naughton JL, Brundage B, Schiller NB. The heart in diabetes. West F Med 1984; 14:583-93.

19 Beller GA, Gibson RS. Sensitivity, specificity and prognostic significance of non-invasive testing for occult or known coronary disease. Prog Cardiovasc Dis $1987 ; 23(4): 241-70$.

(Accepted 25 April 1990

\title{
Infection with human $T$ cell leukaemia/lymphoma virus type I in patients attending an antenatal clinic in London
}

\author{
Jennifer H C Tosswill, A E Ades, \\ Catherine Peckham, Philip P Mortimer, \\ Jonathan N Weber
}

\author{
Virus Reference \\ Laboratory, Central Public \\ Health Laboratory, \\ London NW9 5HT \\ Jennifer H C Tosswill, MSC, \\ senior microbiologist \\ Philip P Mortimer, \\ FRCPATH, director

\section{Institute of Child Health, London WC1 \\ A E Ades, PHD, senior lecturer in medical statistics \\ Catherine Peckham, MD, professor of paediatric epidemiology}

\section{Department of Medicine,} Royal Postgraduate

Medical School, London W12 0HS

Jonathan N Weber, MRCP, senior lecturer in infectious diseases

Correspondence to: Dr Weber.

Br.1Yed J 1990;301:95-6
Infection with human $\mathrm{T}$ cell leukaemia/lymphoma virus type $I$ has often been reported in British adults originating from the Caribbean islands, ${ }^{1}$ though few data exist on the prevalence of the virus in unselected populations in the United Kingdom. In recent studies in north London fewer than $0.02 \%$ of blood donors were found to be positive for the virus (J A J Barbara, personal communication).

We assessed the prevalence of antibody to human $T$ cell leukaemia/lymphoma virus type $I$ in women attending an antenatal clinic in an area of London with an ethnically heterogeneous population and investigated whether seropositivity was confined to groups known to be at risk of carrying the virus.

\section{Patients, methods, and results}

We collected serum samples from 2956 consecutive women attending an antenatal clinic in London during 1980. The ethnic origin, country of birth, and age of each patient were recorded. The analysis was based on the 2893 women for whom complete data and sufficient serum were available. Ethical permission had been obtained for the study.

The serum was initially tested for the presence of antibody to human $T$ cell leukaemia/lymphoma virus type I by gelatin particle agglutination (Fujirebio), a very sensitive but not very specific test. All reactive samples were further tested by enzyme linked immunosorbent assay (ELISA) (Abbott and Du Pont) and competitive and IgG capture radioimmunoassay (Virus Reference Laboratory in house assays). Samples that gave a reaction in one or more of these additional assays were then tested by western blot analysis (Biotechnology Research); those that reacted with envelope proteins in the blot were confirmed as positive.

Of the 2893 serum samples tested, 130 were reactive by gelatin particle agglutination; 27 of these were reactive in additional assays, but only six were reactive in all assays including western blot and so were confirmed as positive. The results were analysed by ethnic origin and country of birth of the patients (table). All of the women confirmed as being positive for antibody to the virus were black and had been born outside the United Kingdom. The proportion of black women confirmed as positive was significantly greater in those who had been born in the Caribbean than in those who had been born in the United Kingdom $(p=0.049$, Fisher's exact one tailed test). The women who had been born in the Caribbean were, however, on average 6.6 years older than those who had been born in the United Kingdom. The numbers were low in all the groups of black women, but the results were consistent with a fairly high prevalence of antibody to the virus based on the $95 \%$ confidence interval.

\section{Comment}

In this group of antenatal patients infection with human $\mathrm{T}$ cell leukaemia/lymphoma virus type I was confined to ethnic groups already known to be at risk of carrying the virus - that is, black women who had been born in the West Indies or Africa. The highest prevalence of infection (1.9\%) was found in black women who had been born in the West Indies, which is

Distribution of antibody to human $T$ cell leukaemiallymphoma virus type I in antenatal patients according to their ethnic origin

\begin{tabular}{|c|c|c|c|c|c|c|}
\hline Ethnic origin & $\begin{array}{l}\text { Region } \\
\text { of } \\
\text { birth }\end{array}$ & $\begin{array}{c}\text { No of } \\
\text { patients } \\
(n=2893)\end{array}$ & $\begin{array}{l}\text { Mean } \\
\text { age } \\
\text { (years) }\end{array}$ & $\begin{array}{l}\text { No }(\%) \text { of serum samples } \\
\text { reactive but } \\
\text { not confirmed as positive }\end{array}$ & $\begin{array}{l}\text { No }(\%) \text { of samples } \\
\text { confirmed as } \\
\text { positive }\end{array}$ & $\begin{array}{c}\text { 95\% Confidence interval } \\
(\%)\end{array}$ \\
\hline \multirow{2}{*}{ Asian } & $\int$ Asia & 605 & $25 \cdot 5$ & $5: 0 \cdot 8$ & & 0.0 to 0.6 \\
\hline & Africa & 389 & $25 \cdot 9$ & $1(0.3)$ & & 0.0 to 0.9 \\
\hline \multirow[t]{2}{*}{ White } & United Kingdom & 997 & $25 \cdot 9$ & $3(0 \cdot 3)$ & & 0.0 to 0.4 \\
\hline & United Kingdom & 214 & $19 \cdot 5$ & $2(0.9)$ & & 0.0 to 1.7 \\
\hline \multirow[t]{2}{*}{ Black } & Africa & 135 & $27 \cdot 5$ & $5(3 \cdot 7)$ & $1(0 \cdot 7)$ & $0 \cdot 0$ to $4 \cdot 1$ \\
\hline & Caribbean & 260 & $26 \cdot 1$ & $2(0 \cdot 8)$ & $5(1.9)$ & 0.6 to 4.5 \\
\hline Other & Various & 293 & $28 \cdot 2$ & $3(1 \cdot 8)$ & & 0.0 to $1 \cdot 2$ \\
\hline
\end{tabular}

